\title{
RESEARCH
}

Open Access

\section{Association of gravity drainage and complications following Whipple: an analysis of the ACS-NSQIP targeted database}

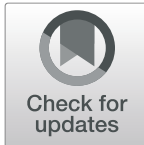

Bradley R. Hall ${ }^{1}$, Zachary H. Egr ${ }^{2}$, Robert W. Krell ${ }^{3}$, James C. Padussis ${ }^{1}$, Valerie K. Shostrom ${ }^{4}$, Chandrakanth Are and Bradley N. Reames ${ }^{1,4^{*}}$

\begin{abstract}
Background: The optimal type of operative drainage following pancreaticoduodenectomy (PD) remains unclear. Our objective is to investigate risk associated with closed drainage techniques (passive [gravity] vs. suction) after PD.

Methods: We assessed operative drainage techniques utilized in patients undergoing PD in the ACS-NSQIP pancreas-targeted database from 2016 to 2018. Using multivariable logistic regression to adjust for characteristics of the patient, procedure, and pancreas, we examined the association between use of gravity drainage and postoperative outcomes.

Results: We identified 9665 patients with drains following PD from 2016 to 2018, of which $12.7 \%$ received gravity drainage. $61.0 \%$ had a diagnosis of adenocarcinoma or pancreatitis, $26.5 \%$ had a duct $<3 \mathrm{~mm}$, and $43.5 \%$ had a soft or intermediate gland. After multivariable adjustment, gravity drainage was associated with decreased rates of postoperative pancreatic fistula (odds ratio [OR] 0.779, 95\% confidence interval [CI] 0.653-0.930, $p=0.006$ ), delayed gastric emptying (OR $0.830,95 \% \mathrm{Cl} 0.693-0.988, p=0.036)$, superficial SSI (OR 0.741, 95\% Cl 0.572-0.959, $p=0.023)$, organ space SSI (OR 0.791, 95\% Cl 0.658-0.951, $p=0.012)$, and readmission (OR 0.807, 95\% Cl 0.679-0.958, $p=0.014$ ) following PD.
\end{abstract}

Conclusions: Gravity drainage is independently associated with decreased rates of CR-POPF, DGE, SSI, and readmission following PD. Additional prospective research is necessary to better understand the preferred drainage technique following PD.

Keywords: Pancreatic ductal adenocarcinoma, Drain, Suction, Gravity, Morbidity

\footnotetext{
* Correspondence: bradley.reames@unmc.edu

'Division of Surgical Oncology, Department of Surgery, University of

Nebraska Medical Center, 986880 Nebraska Medical Center, Omaha, NE 68198, USA

${ }^{4}$ College of Public Health, Department of Biostatistics, University of Nebraska Medical Center, Omaha, NE, USA

Full list of author information is available at the end of the article
}

(c) The Author(s). 2021 Open Access This article is licensed under a Creative Commons Attribution 4.0 International License, which permits use, sharing, adaptation, distribution and reproduction in any medium or format, as long as you give appropriate credit to the original author(s) and the source, provide a link to the Creative Commons licence, and indicate if changes were made. The images or other third party material in this article are included in the article's Creative Commons licence, unless indicated otherwise in a credit line to the material. If material is not included in the article's Creative Commons licence and your intended use is not permitted by statutory regulation or exceeds the permitted use, you will need to obtain permission directly from the copyright holder. To view a copy of this licence, visit http://creativecommons.org/licenses/by/4.0/. The Creative Commons Public Domain Dedication waiver (http://creativecommons.org/publicdomain/zero/1.0/) applies to the data made available in this article, unless otherwise stated in a credit line to the data. 


\section{Introduction}

The approach to abdominal drainage after a major abdominal surgery has evolved in recent decades. While many procedures employ selective drainage, drains are still commonly utilized after pancreatectomy [1-6]. Reasons commonly given for routine pancreatic drainage are early diagnosis of and management of pancreatic fistula, which is a potentially devastating complication [7]. Whether operative drains help prevent or manage complications remains debated. While some clinical trials addressing this question showed similar complications and mortality regardless of closed-suction drain usage, others were stopped early after showing increased mortality in patients without drains [8-10]. As a result, drain placement in pancreatectomy remains discretionary and subject to institutional and surgeon preference.

Regardless of the decision to utilize operative drains, the preferred method of closed drainage following pancreatectomy is poorly understood. Two of the most commonly utilized methods are suction and gravity drainage. The most commonly cited reason for using gravity drainage is avoiding suction near the pancreaticoenteric anastomosis, which may cause or contribute to the development of postoperative pancreatic fistula (POPF) [11-14]. Supporting this argument are institutional series associating higher leak rates with prolonged suction drainage and decreased leak rates associated with gravity drainage $[12,13]$. In contrast, recent publications have not demonstrated differences in POPF rates between closed-suction and gravity drains in mixed cohorts of pancreatectomy [15] or among a small cohort of pancreaticoduodenectomy (PD) alone [16].

A better understanding of the relationship between drain suction and complications following PD could inform best practice and possibly improve patient outcomes. Therefore, in this study, we sought to investigate the relationship between type of drainage and procedure-specific complications following $\mathrm{PD}$, using a validated international surgical registry, similar to prior reports. However, as recent studies have been limited by heterogenous cohorts, methodological considerations, or small sample sizes, in this study, we address these limitations by using a rigorous and previously published definition of POPF congruent with the revised International Study Group of Pancreatic Fistula (ISGPS) definition of 2016, and we evaluate a large homogeneous cohort of PD only.

\section{Material and methods}

\section{Ethics approval and consent to participate}

All data within this study was obtained from a registry comprised of de-identified information. As such, it was exempt from review by our University's Institutional
Review Board. Similarly, since no individual patient data was analyzed, individual patient consent was forgone.

\section{Data source}

The American College of Surgeons National Surgical Quality Improvement Program (ACS-NSQIP) is a clinical registry that collects preoperative data and 30-day outcomes for patients undergoing surgical procedures from 713 hospitals around the world, of which 581 are located in the USA [17]. Details regarding data abstraction and validity have been reported elsewhere [18]. Beginning in 2014, the ACS-NSQIP offered proceduretargeted data collection for pancreatectomy procedures for select hospitals [17]. The procedure-targeted dataset includes $100 \%$ case capture for pancreatectomy procedures and additional preoperative, intraoperative, and postoperative variables. For this study, we merged the pancreatectomy procedure-targeted dataset from 2016 to 2018 with the contemporaneous ACS-NSQIP Participant User Data File.

\section{Availability of data and materials}

All data analyzed in this study originated from the ACSNSQIP Participant User Data File. This data may be obtained by requesting the Participant User Data Files from the American College of Surgeons at https://www.facs. org/quality-programs/acs-nsqip.

\section{Study population and variables}

We identified all adults undergoing PD that also received operative drain placement from 2016 to 2018 in ACS-NSQIP participating hospitals with pancreatectomy-targeted data collection using relevant Current Procedural Terminology (CPT) codes. We excluded patients undergoing emergency surgery and patients with open drainage systems or missing data regarding drainage.

Available patient characteristics included age, gender, race, American Society of Anesthesiologists (ASA) class, diabetes, and administration of neoadjuvant chemotherapy or radiation. Operative data included surgical approach (open vs. minimally invasive), wound classification, prophylactic antibiotic usage, wound protector usage, operative duration, pancreatic duct diameter, gland texture, vascular reconstruction, type of pancreaticoenterostomy, red blood cell transfusion on postoperative day (POD) 0 , and pancreatic pathology.

\section{Postoperative outcomes}

The primary outcome of this study was clinically relevant POPF (CR-POPF) in accordance with the updated ISGPF definition from 2016 [19]. As ACS-NSQIP does not specifically code pancreatic fistula according to this definition, the variable CR-POPF was created using 
available registry data as previously described in the literature $[20,21]$. In brief, patients defined as having a "pancreatic fistula" or those with a drain amylase $>300$ $\mathrm{U} / \mathrm{dL}$ on or after POD 3 were considered to have a CRPOPF if they met any of the following criteria: (1) drain in place for $>21$ days or $>14$ days with prolonged hospital stay > 21 days; (2) postoperative percutaneous drain placed, or (3) presence of organ space surgical site infection (SSI), reoperation, sepsis, shock, or multisystem organ failure [20, 21].

Secondary outcomes of interest included delayed gastric emptying (DGE), percutaneous drain placement, reoperation, readmission, prolonged length of stay (LOS), mortality, and surgical site compilations including superficial, deep, or organ space SSI; sepsis; and septic shock. Delayed gastric emptying was defined by NSQIP as no oral intake by POD 14 or nasogastric/gastric drainage or replacement after POD 7. Prolonged length of stay was defined as a LOS $>75$ th percentile. Mortality was defined as death within 30 days of surgery or prior to discharge. For all infectious outcomes, a complication was documented if it occurred within 30 days of the operation and was not documented as present on admission.

\section{Statistical analysis}

Student's $t$-test, Chi-square, or Fisher's exact tests were used as appropriate to evaluate univariable associations between primary and secondary outcomes and the type of operative drainage (suction vs. gravity). We then assessed the influence of drainage type on CR-POPF and secondary outcomes using multivariable logistic regression, adjusting for patient demographics, comorbidities, and operative differences across groups. Patient and operative characteristics associated with CR-POPF and secondary outcomes were identified using stepwise logistic regression with backwards selection to ensure appropriate model fit. Candidate variables in the model included patient age, gender, race, smoking, diabetes, year of procedure, ASA classification $\leq 2$, wound classification $\geq 3$, neoadjuvant chemotherapy, neoadjuvant radiation, surgical approach, vascular reconstruction, pancreas reconstruction, surgical pathology, pancreatic gland texture and pancreatic duct size, and POD 0 transfusion. For modeling purposes, minimally invasive procedures that converted to open were considered open surgery. For the final analysis and in accordance with previous literature evaluating pancreatic fistula risk [20, 21], surgical pathology was dichotomized as "adenocarcinoma or pancreatitis" or "other," and pancreatic gland texture was dichotomized as "hard" or "intermediate/soft" [22]. As the estimated blood loss of the operation was not available, associations with this variable were tested using the administration of a red blood cell transfusion on POD 0.
Variables from the stepwise regression model with coefficient $p$-values $<0.05$ were then used in a second multivariable model including drainage type. In our model assessing drainage on CR-POPF, the variable duct size (< $3 \mathrm{~mm}, \geq 3 \mathrm{~mm}$, or unknown), firm gland texture, surgical pathology, and POD 0 transfusion were forced into the model regardless of significance. To account for missing data, particularly within variables above known to influence the risk of CR-POPF, we performed multiple sensitivity analyses. First, the analysis was performed only using observations with complete data for surgical pathology, gland texture, duct size, and POD 0 transfusion. Second, multiple imputation was used to account for the missing data within each variable. As the results of both analyses were qualitatively identical to the primary analysis, only the results of the primary analysis are presented here. Statistical analyses were performed using SAS v9.4 (SAS Institute Inc., Vary, NC, USA). For all statistical tests, $p$ values are two-tailed, and alpha is set at 0.05 .

\section{Results}

A total of 9665 PD patients received operative drainage between 2016 and 2018 at ACS-NSQIP targeted pancreatectomy participating hospitals. Demographic, operative, and pathologic characteristics, according to type of drainage, are shown in Table 1 . Of 9665 patients with operative drains, 1224 (12.7\%) had drains to gravity. Patients with closed-suction drains were more likely to have ASA classification 3 or 4 (78.1\% vs. $74.3 \%, p=0.002)$, received neoadjuvant chemotherapy $(22.3 \%$, vs. $18.4 \%, p=0.002)$ and radiation $(9.2 \%$ vs. $6.2 \%, p=0.001)$, underwent more vascular resections $(17.3 \%$ vs. $13.8 \%, p=0.003)$, and more frequently had duct-mucosa pancreaticojejunostomy reconstructions $(89.1 \%$ vs. $86.8 \%, p=0.015)$.

Results from the univariable analysis of postoperative drain management and outcomes are displayed in Table 2. Notably, rates of CR-POPF were more common in the suction group as compared to the gravity group ( $16.5 \%$ vs. $13.7 \%, p=0.015)$. SSIs were more frequent in the closed-suction drain group, particularly superficial SSI $(7.3 \%$ vs. $5.6 \%, p=0.033)$ and organ space SSI $(14.9 \%$ vs. $12.4 \%, p=0.022)$. Unplanned readmission (17.6\% vs. $14.1 \%, p=0.008)$ and DGE (16.6\% vs. $14.0 \%, p=0.019$ ) were also more common in the closed-suction group. Length of stay was similar between groups. Notably, no significant differences in rates of percutaneous drain placement, reoperation, sepsis, or mortality were observed.

Table 3 displays multivariable associations between patient and disease characteristics and the primary outcome, CR-POPF, in the final logistic regression model. After adjusting for relevant patient and treatment 
Table 1 Patient characteristics and operative details

\begin{tabular}{|c|c|c|c|c|c|}
\hline \multirow[t]{2}{*}{ Variable } & \multicolumn{2}{|l|}{$\begin{array}{l}\text { Suction } \\
(N=8441)\end{array}$} & \multicolumn{2}{|l|}{$\begin{array}{l}\text { Gravity } \\
(N=1224)\end{array}$} & \multirow[t]{2}{*}{$p$-value } \\
\hline & Number & $\overline{\text { Percent }}$ & Number & $\overline{\text { Percent }}$ & \\
\hline Age (median, [IQR]) & $67[59,73]$ & & $67[58,73]$ & & 0.048 \\
\hline Female & 3891 & $46.1 \%$ & 598 & $48.9 \%$ & 0.070 \\
\hline Race & & & & & 0.293 \\
\hline White & 6284 & $74.4 \%$ & 894 & $73.0 \%$ & \\
\hline Unknown/other & 2157 & $25.6 \%$ & 330 & $27.0 \%$ & \\
\hline Smoking & & & & & 0.048 \\
\hline Yes & 1461 & $17.3 \%$ & 184 & $15.0 \%$ & \\
\hline No & 6980 & $82.7 \%$ & 1040 & $85.0 \%$ & \\
\hline Diabetes & & & & & 0.146 \\
\hline Yes & 2207 & $26.2 \%$ & 344 & $28.1 \%$ & \\
\hline No & 6234 & $73.8 \%$ & 880 & $71.2 \%$ & \\
\hline Operation year & & & & & $<0.001$ \\
\hline 2016 & 2581 & $30.6 \%$ & 498 & $40.7 \%$ & \\
\hline 2017 & 2853 & $33.8 \%$ & 378 & $30.9 \%$ & \\
\hline 2018 & 3007 & $35.6 \%$ & 348 & $28.4 \%$ & \\
\hline ASA class & & & & & 0.002 \\
\hline 1 or 2 & 1845 & $21.9 \%$ & 315 & $25.7 \%$ & \\
\hline 3 or 4 & 6596 & $78.1 \%$ & 909 & $74.3 \%$ & \\
\hline Wound class & & & & & $<0.001$ \\
\hline 1 or 2 & 6802 & $80.6 \%$ & 1038 & $84.8 \%$ & \\
\hline 3 or 4 & 1639 & $19.4 \%$ & 186 & $15.2 \%$ & \\
\hline Neoadjuvant chemotherapy & & & & & 0.002 \\
\hline Yes & 1884 & $22.3 \%$ & 225 & $18.4 \%$ & \\
\hline No & 6557 & $77.7 \%$ & 999 & $81.6 \%$ & \\
\hline Neoadjuvant radiation therapy & & & & & 0.001 \\
\hline Yes & 777 & $9.2 \%$ & 76 & $6.2 \%$ & \\
\hline No & 7664 & $90.8 \%$ & 1148 & $93.8 \%$ & \\
\hline Approach (combined categories) & & & & & 0.013 \\
\hline Open & 7925 & $93.9 \%$ & 1171 & $95.7 \%$ & \\
\hline Minimally invasive & 516 & $6.1 \%$ & 53 & $4.3 \%$ & \\
\hline Pancreatic duct diameter & & & & & $<0.001$ \\
\hline$<3 \mathrm{~mm}$ & 2254 & $26.7 \%$ & 324 & $26.5 \%$ & \\
\hline$\geq 3 \mathrm{~mm}$ & 4697 & $55.6 \%$ & 615 & $50.2 \%$ & \\
\hline Unknown & 1490 & $17.7 \%$ & 285 & $23.3 \%$ & \\
\hline Pancreatic gland texture & & & & & $<0.001$ \\
\hline Soft/intermediate & 3890 & $46.1 \%$ & 533 & $43.5 \%$ & \\
\hline Hard & 2797 & $33.1 \%$ & 336 & $27.5 \%$ & \\
\hline Unknown & 1754 & $20.8 \%$ & 335 & $27.4 \%$ & \\
\hline Pancreatic pathology & & & & & 0.264 \\
\hline Adenocarcinoma or pancreatitis & 5010 & $59.4 \%$ & 747 & $61.0 \%$ & \\
\hline Other or unknown & 3431 & $40.6 \%$ & 477 & $39.0 \%$ & \\
\hline Transfusion on POD0 & & & & & 0.001 \\
\hline
\end{tabular}


Table 1 Patient characteristics and operative details (Continued)

\begin{tabular}{|c|c|c|c|c|c|}
\hline \multirow[t]{2}{*}{ Variable } & \multicolumn{2}{|l|}{$\begin{array}{l}\text { Suction } \\
(N=8441)\end{array}$} & \multicolumn{2}{|l|}{$\begin{array}{l}\text { Gravity } \\
(N=1224)\end{array}$} & \multirow[t]{2}{*}{$p$-value } \\
\hline & Number & Percent & Number & Percent & \\
\hline Yes & 1169 & $13.8 \%$ & 127 & $12.1 \%$ & \\
\hline No & 7272 & $86.2 \%$ & 1097 & $83.9 \%$ & \\
\hline Pathologic detail & & & & & -- \\
\hline Pancreatic adenocarcinoma & 4614 & $55.4 \%$ & 687 & $56.9 \%$ & \\
\hline Ampullary carcinoma & 683 & $8.2 \%$ & 88 & $7.3 \%$ & \\
\hline Duodenal carcinoma & 255 & $3.1 \%$ & 32 & $2.7 \%$ & \\
\hline Neuroendocrine & 550 & $6.6 \%$ & 88 & $7.3 \%$ & \\
\hline IPMN-invasive & 188 & $2.3 \%$ & 17 & $1.4 \%$ & \\
\hline Distal cholangiocarcinoma & 273 & $3.3 \%$ & 24 & $2.0 \%$ & \\
\hline Malignant other & 419 & $5.0 \%$ & 50 & $4.1 \%$ & \\
\hline Chronic pancreatitis & 288 & $3.5 \%$ & 51 & $4.2 \%$ & \\
\hline IPMN-noninvasive & 534 & $6.4 \%$ & 96 & $7.9 \%$ & \\
\hline Mucinous cystic neoplasm & 59 & $0.7 \%$ & 5 & $0.4 \%$ & \\
\hline Serous cystadenoma & 78 & $0.9 \%$ & 14 & $1.2 \%$ & \\
\hline Solid pseudopapillary neoplasm & 43 & $0.5 \%$ & 7 & $0.6 \%$ & \\
\hline Benign other & 342 & $4.1 \%$ & 49 & $4.1 \%$ & \\
\hline Pancreatic reconstruction & & & & & 0.015 \\
\hline Pancreaticojejunal duct-to-mucosal & 7521 & $89.1 \%$ & 1062 & $86.8 \%$ & \\
\hline Pancreaticojejunal invagination or pancreaticogastrostomy & 920 & $10.9 \%$ & 162 & $13.2 \%$ & \\
\hline Vascular reconstruction (any) & 1457 & $17.3 \%$ & 169 & $13.8 \%$ & 0.003 \\
\hline T stage & & & & & -- \\
\hline T0/Tis & 110 & $1.3 \%$ & 8 & $0.7 \%$ & \\
\hline T1 & 899 & $10.9 \%$ & 125 & $10.4 \%$ & \\
\hline $\mathrm{T} 2$ & 1777 & $21.5 \%$ & 272 & $22.7 \%$ & \\
\hline T3 & 3629 & $43.8 \%$ & 502 & $41.8 \%$ & \\
\hline T4 & 381 & $4.6 \%$ & 47 & $3.9 \%$ & \\
\hline Tx/unknown & 1484 & $17.9 \%$ & 246 & $20.5 \%$ & \\
\hline N stage & & & & & -- \\
\hline No & 2689 & $32.7 \%$ & 369 & $31.0 \%$ & \\
\hline $\mathrm{N} 1$ & 4029 & $49.1 \%$ & 573 & $48.2 \%$ & \\
\hline Nx/unknown & 1493 & $18.2 \%$ & 248 & $20.8 \%$ & \\
\hline M stage & & & & & -- \\
\hline $\mathrm{Mo} / \mathrm{Mx}$ & 5381 & $70.2 \%$ & 615 & $61.6 \%$ & \\
\hline M1 & 145 & $1.9 \%$ & 28 & $2.8 \%$ & \\
\hline Unknown & 2136 & $27.9 \%$ & 356 & $35.6 \%$ & \\
\hline
\end{tabular}

characteristics, including surgical pathology, pancreatic gland texture and duct size, and transfusion on POD 0 , use of closed-suction drainage systems is independently associated with risk of CR-POPF (adjusted odds ratio 1.283, 95\% confidence interval 1.075-1.532, $p=0.006$ ). Other characteristics significantly associated with risk of CR-POPF in the model include small pancreatic duct size, soft/intermediate pancreatic gland texture, surgical pathology other than PDAC or pancreatitis, gender, white race, diabetes, neoadjuvant chemotherapy and radiation, minimally invasive surgery, and BMI.

The adjusted rates of postoperative outcomes for suction and gravity drainage are displayed in Fig. 1, while the corresponding odds ratios for gravity drainage are shown in Table 4. After adjusting for patient and operative risk factors, the rates of CR-POPF 
Table 2 Univariable associations between drain management and outcomes for the entire cohort

\begin{tabular}{llll}
\hline Outcome & $\begin{array}{l}\text { Suction } \\
(\mathbf{N = 8 4 4 1 )}\end{array}$ & $\begin{array}{l}\text { Gravity } \\
(\mathbf{N = 1 2 2 4 )}\end{array}$ & $\boldsymbol{p}$-value \\
\hline CR-POPF & $1389(16.5 \%)$ & $168(13.7 \%)$ & $\mathbf{0 . 0 1 5}$ \\
Mortality & $158(1.9 \%)$ & $14(1.1 \%)$ & 0.072 \\
Surgical site infection (SSI) & & & \\
$\quad$ Superficial & $617(7.3 \%)$ & $69(5.6 \%)$ & $\mathbf{0 . 0 3 3}$ \\
$\quad$ Deep incisional & $83(1.0 \%)$ & $7(0.6 \%)$ & 0.161 \\
$\quad$ Organ-space & $1257(14.9 \%)$ & $152(12.4 \%)$ & $\mathbf{0 . 0 2 2}$ \\
$\quad$ Any SSI & $1801(21.3 \%)$ & $210(17.2 \%)$ & $\mathbf{0 . 0 0 1}$ \\
Sepsis & $570(6.7 \%)$ & $72(5.9 \%)$ & 0.253 \\
Reoperation & $475(5.6 \%)$ & $54(4.4 \%)$ & 0.081 \\
Unplanned readmission & $1486(17.6 \%)$ & $173(14.1 \%)$ & $\mathbf{0 . 0 0 8}$ \\
Delayed gastric emptying & $1403(16.6 \%)$ & $171(14.0 \%)$ & $\mathbf{0 . 0 1 9}$ \\
Percutaneous drain placement & $1047(12.4 \%)$ & $153(12.5 \%)$ & 0.924 \\
Prolonged length of stay ${ }^{a}$ & $2318(27.8 \%)$ & $313(25.9 \%)$ & 0.165 \\
\hline
\end{tabular}

${ }^{a}$ Greater than or equal to 12 days

$C R-P O P F$ clinically relevant postoperative pancreatic fistula, SSI surgical site infection

(10.7\% vs. $8.5 \%, p=0.006)$, delayed gastric emptying (16.1\% vs. $13.7 \%, p=0.036)$, any SSI $(22.4 \%$ vs. $17.7 \%$, $p<0.001)$, superficial SSI $(9.1 \%$ vs. $6.9 \%, p=0.023)$, organ space SSI (14.2 vs. $11.8, p=0.012)$, and readmission $(20.8 \%$ vs. $17.4 \%, p=0.014)$ were lower in the gravity drainage group as compared to the closedsuction group. No adverse outcomes were more common in the gravity cohort. The odds of experiencing CR-POPF were statistically significantly lower in patients receiving gravity drainage (adjusted odds ratio [AOR] 0.779, 95\% confidence interval [CI] 0.6530.930), as were the odds of DGE (AOR 0.830, 95\% CI $0.693-0.988$ ), any SSI (AOR 0.741, 95\% CI 0.6310.870), superficial SSI (AR 0.741, 95\% CI $0.572-$ 0.959), organ space SSI (AR 0.791, 95\% CI 0.6580.951), and readmission (AOR 0.807, 95\% CI 0.6790.958).

\section{Discussion}

This analysis of the ACS-NSQIP procedure-targeted database demonstrates that among patients with operative drain placement after PD, closed-suction drainage is independently associated with higher rates of CR-POPF (10.7\% vs. $8.5 \%)$, DGE (16.1 vs. $13.7 \%)$, SSI ( $22.4 \%$ vs. $17.7 \%)$, and readmission (20.8\% vs. $17.4 \%)$. Given the sparse literature on this subject and the mechanistic plausibility of the association, the results of this study raise important questions about the type of operative drainage utilized following $\mathrm{PD}$ and warrant further investigation.

Few studies have been published comparing gravity and closed-suction drainage in pancreas surgery, and

Table 3 Multivariable associations between drain management and CR-POPF

\begin{tabular}{|c|c|c|c|c|}
\hline \multirow[t]{2}{*}{ Variable } & \multirow[t]{2}{*}{ AOR } & \multicolumn{2}{|l|}{$95 \% \mathrm{Cl}$} & \multirow[t]{2}{*}{$p$-value } \\
\hline & & Lower & Upper & \\
\hline Closed-suction drainage & 1.283 & 1.075 & 1.532 & 0.0058 \\
\hline \multicolumn{5}{|l|}{ Pancreatic duct size } \\
\hline$>3 \mathrm{~mm}$ & Ref & Ref & Ref & Ref \\
\hline$<3 \mathrm{~mm}$ & 1.366 & 1.199 & 1.555 & $<.0001$ \\
\hline Unknown & 1.277 & 1.068 & 1.527 & 0.007 \\
\hline \multicolumn{5}{|l|}{ Pancreatic gland texture } \\
\hline Hard & Ref & Ref & Ref & Ref \\
\hline Soft/intermediate & 2.596 & 2.212 & 3.046 & $<.0001$ \\
\hline Unknown & 1.952 & 1.598 & 2.384 & $<.0001$ \\
\hline Pathology other than PDAC or pancreatitis & 1.372 & 1.217 & 1.548 & $<.0001$ \\
\hline POD 0 transfusion & 1.113 & 0.941 & 1.316 & 0.2121 \\
\hline Female & 0.697 & 0.622 & 0.781 & $<.0001$ \\
\hline White race & 1.145 & 1.010 & 1.299 & 0.0345 \\
\hline Diabetes & 0.779 & 0.681 & 0.892 & 0.0003 \\
\hline Neoadjuvant chemotherapy & 0.751 & 0.623 & 0.906 & 0.0027 \\
\hline Neoadjuvant radiation & 0.707 & 0.527 & 0.949 & 0.0211 \\
\hline Minimally invasive surgery & 0.615 & 0.471 & 0.805 & 0.0004 \\
\hline Pancreatic reconstruction other than duct to mucosa pancreaticojejunostomy & 1.122 & 0.947 & 1.329 & 0.1829 \\
\hline BMI & 1.026 & 1.017 & 1.036 & $<.0001$ \\
\hline
\end{tabular}

CR-POPF clinically relevant postoperative pancreatic fistula, $P D A C$ pancreatic ductal adenocarcinoma, $P O D$ postoperative day 


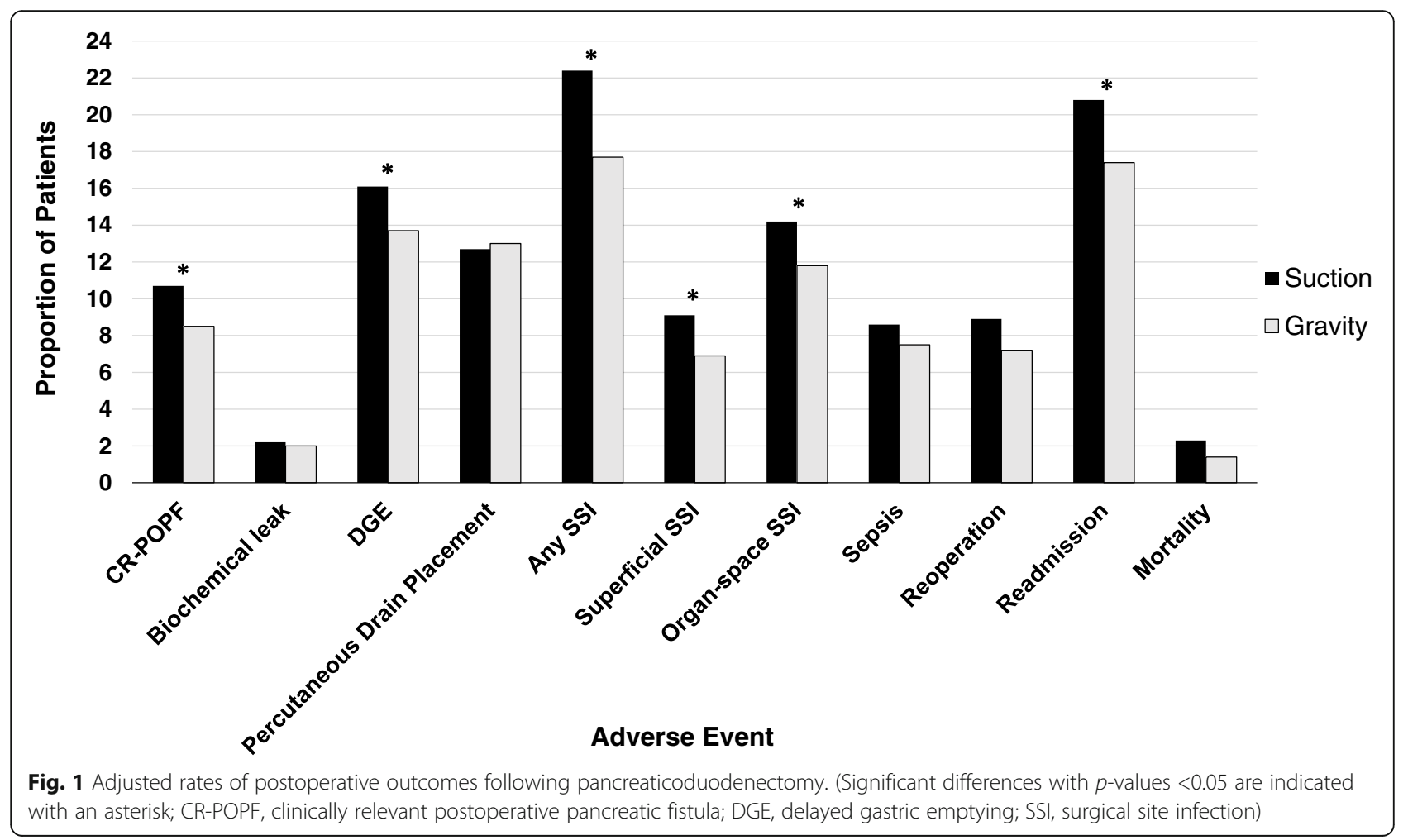

much of the literature to date suffers from substantial limitations. In the single-institution retrospective study by Schmidt and colleagues, gravity drainage was associated with lower rates of POPF ( $14 \%$ vs. $3 \%$ ), but also correlated with higher volume surgeons, raising concerns about gravity drainage acting as a surrogate for procedure volume [13]. Though multiple recently published studies suggest no differences in outcomes between suction or gravity closed-drainage systems $[15,16,23]$, each

Table 4 Adjusted odds ratios (AOR) for gravity drainage and outcomes

\begin{tabular}{lllll}
\hline Outcome & AOR & \multicolumn{2}{c}{$\mathbf{9 5 \% \mathrm { Cl }}$} & p-value \\
\cline { 3 - 4 } & & Lower & Upper & \\
\hline CR-POPF & 0.779 & 0.653 & 0.930 & $\mathbf{0 . 0 0 5 8}$ \\
Biochemical leak & 0.919 & 0.693 & 1.219 & 0.556 \\
Delayed gastric emptying & 0.830 & 0.693 & 0.988 & $\mathbf{0 . 0 3 6}$ \\
Percutaneous drain placement & 1.024 & 0.851 & 1.233 & 0.800 \\
Any surgical site infection (SSI) & 0.741 & 0.631 & 0.870 & $<\mathbf{0 . 0 0 1}$ \\
$\quad$ Superficial SSI & 0.741 & 0.572 & 0.959 & $\mathbf{0 . 0 2 3}$ \\
$\quad$ Organ-space SSI & 0.791 & 0.658 & 0.951 & $\mathbf{0 . 0 1 2}$ \\
Sepsis & 0.956 & 0.664 & 1.105 & 0.233 \\
Reoperation & 0.794 & 0.594 & 1.062 & 0.120 \\
Readmission & 0.807 & 0.679 & 0.958 & $\mathbf{0 . 0 1 4}$ \\
Mortality & 0.640 & 0.368 & 1.112 & 0.113 \\
\hline
\end{tabular}

CR-POPF clinically relevant postoperative pancreatic fistula, $S S$ I surgical site infection of these studies has significant limitations that warrant consideration. Previous randomized trials evaluating drainage type have been limited by small sample size or showed rates of CR-POPF higher than those typically seen in US hospitals [23]. The study by Kone et al. included only the 2016-2017 ACS-NSQIP pancreastargeted database and analyzed both PD and distal pancreatectomy together. In addition, the authors used the ACS-NSQIP definition of CR-POPF, which is not congruent with the updated 2016 ISGPS definition [20], and the use of propensity score matching resulted in the loss of $>10 \%$ of their sample size. As previous literature clearly demonstrates that POPF risk differs between PD and distal pancreatectomy $[9,10]$, studies of pancreatectomy investigating CR-POPF should be performed on homogeneous populations to minimize confounding of the results. Lemke and colleagues, on the other hand, used a more rigorous definition of CR-POPF and a more homogenous population of PD patients. However, the power of this study is severely limited by its small sample size, as their final multivariable analysis only included 1787 patients, and use of coarsened exact matching further reduced their final cohort to $268 \mathrm{pa}$ tients. Not unexpectedly, no association between drainage technique and CR-POPF was observed.

Our study addresses the limitations of these previous studies by using 3 years of a large, validated, international surgical registry to increase sample size; studies a selected population of PD procedures only; and utilizes 
a rigorous previously published definition of CR-POPF congruent with the ISGPS update of 2016 [20, 21]. Similar to recent studies above, the results herein are consistent in demonstrating a small decrease in rates of CRPOPF associated with use of gravity drainage when compared to closed-suction drainage. However, in contrast recent work, the findings of this study (with a larger sample and analyses maximizing use of all available patients) do suggest a statistically significant relationship between gravity drainage and consistently lower rates of CR-POPF, and multiple other related complications, following PD.

In pancreas surgery, much of the literature evaluating operative drainage is focused on addressing whether drains are necessary at all, and results remain conflicted. In one of the earliest trials addressing this issue, Conlon et al. found no differences in overall morbidity or mortality in patients undergoing PD or distal pancreatectomy regardless of drain usage. In that study, POPF rates were higher in the drained group, suggesting either a detection bias or promotion of fistula formation in drained patients [8]. These results were later supported by findings from Witzigmann and colleagues in the pancreatic drainage (PANDRA) trial, but contradicted by Van Buren et al., who found higher mortality rates in PD patients without operative drains $[9,24,25]$. However, these studies had multiple inherent limitations. Similar to above, considering that the risk associated with operative drainage is procedure-dependent, the inclusion of all partial pancreatectomy patients by Conlon and colleagues may have influenced results [8-10]. The PANDRA trial also suffered from protocol violations and randomization issues [24]. In the later study, the definition of POPF differed from that set forth by the ISGPS, and operative drains were used in approximately $15 \%$ of cases performed by surgeons who were classified as routinely omitting drains [22, 25]. Given the lack of consensus in the literature and the potential for severe morbidity from an uncontrolled pancreatic leak, operative drains are placed in the majority of pancreatectomy cases [7].

Considering that operative drains remain heavily utilized, recent literature has focused on selecting patients for drain omission or identifying patients in whom drains can be safely removed early [22, 26, 27]. Several risk scores are available to stratify patients according to risk of CR-POPF, and many surgeons use these scores to select patients for drain omission [22, 26, 27]. Similarly, several postoperative drain management algorithms employing drain amylase levels are routinely used to identify patients in whom drains can be safely removed $[28,29]$. However, neither the fistula risk calculations nor drain management algorithms published to date account for drainage type. Our study shows a significant association between gravity drainage and decreased CRPOPF after PD. These results suggest that the type of drainage should be considered in the management of PD patients with operative drains.

The mechanistic plausibility of an association between closed-suction drainage and increased rates of CR-POPF is clear and supported by several studies in the literature [11-13]. Whitson and colleagues also measured the force of several types of operative drains and estimated that the pressure applied from a 100-mL Jackson Pratt bulbs was approximately $-125 \mathrm{mmHg}$ [14]. Such force may interfere with the normal healing process in an already tenuous pancreaticoenteric anastomosis. As the development of biochemical leak and CR-POPF are known risk-factors for other post-pancreatectomy complications, such as superficial SSI, organ-space SSI, delayed gastric emptying, and others (readmission), it would be expected that, in a true observation of the world, an analysis reporting an association between gravity drainage and decreased rates of CR-POPF would also report associations with decreased rates of other common downstream complications [30-32]. At the same time, when considering the proposed mechanism, it is not surprising that this analysis failed to reveal an association between drainage method and less frequent, more severe complications (e.g., reoperation, organ failure, or mortality) associated with grade C POPF. Grade C POPF often occur secondary to a major anastomotic failure or disruption that results in a large volume leak and a severe systemic inflammatory response. This type of complication is commonly technical in nature and is unlikely to be influenced by the method of drainage employed.

This study has several limitations. First, the ACSNSQIP procedure-targeted database lacks surgeon- and institution-specific variables that may further influence CR-POPF rates after PD, and as with any clinical registry, there is no doubt of residual confounding in these assessments. For example, it is likely that many individual surgeons do not alternate the type of drainage employed. As a result, the use of gravity drainage could instead represent other unmeasured surgeon- or institution-specific variables (such as volume, technical skill, practice patterns, or culture) known to be associated with outcomes. However, the ACS-NSQIP procedure-targeted database is currently the largest and most reliable contemporaneous clinical registry available to answer this research question, and the multivariable models used herein included patient, pancreas, and procedure-specific variables (components of the FRS) widely accepted to influence risk of POPF. A second and similar limitation of this study is that results may not be generalizable to institutions not participating in ACSNSQIP. However, the institutional cohort of NSQIP is diverse and includes a broad range of hospitals: critical 
access, community, and tertiary academic referral centers, urban and rural, for-profit and not-for-profit. Finally, this is a retrospective analysis, and causation cannot be inferred from our results. While the associations reported herein should only be considered hypothesis generating, the consistency of the associations and the biologic plausibility of the mechanism warrant further investigation.

This is one of the largest studies to date addressing the question of preferred type of operative drainage following PD. Closed-suction drainage was consistently associated with higher rates of multiple pancreatectomyspecific complications, including the primary outcome, CR-POPF, as well as multiple associated downstream complications, such as superficial SSI, organ-space SSI, and DGE. In the context of disparate results from clinical trial data, these results challenge the prevailing practice of closed-suction drainage. If closed-suction drainage is found to contribute to formation of POPF, the results could have important implications for operations beyond PD that involve delicate or technically difficult anastomoses. Additional prospective and (ideally) randomized research is needed to separately address this question both for patients undergoing PD and those undergoing distal pancreatectomy and splenectomy.

\section{Acknowledgements}

The American College of Surgeons National Surgical Quality Improvement Program and the hospitals participating in the ACS NSQIP are the source of the data used herein; they have not verified and are not responsible for the statistical validity of the data analysis or the conclusions derived by the authors. The data that support the findings of this study are available from the American College of Surgeons National Surgical Quality Improvement Program (ACS NSQIP). This research did not receive any specific grant from funding agencies in the public, commercial, or not-for-profit sectors.

\section{Authors' contributions}

BNR was responsible for the initial concept of this study. VKS was responsible for the statistical analysis. CA, JCP, RWK, and BNR provided content expertise. $\mathrm{BRH}$ and $\mathrm{ZHE}$ drafted the manuscript with the assistance of BNR. All authors read, edited, and approved of the manuscript prior to submission and are accountable for the accuracy and integrity of the work.

\section{Funding}

No funding was received by any author for the design of the study, analysis and interpretation of data, writing the manuscript, or any other aspect of this publication.

\section{Availability of data and materials}

This registry database is available to all participating members of the ACS NSQIP collaborative and can be requested here https://www.facs.org/qualityprograms/acs-nsqip.

\section{Declarations}

\section{Ethics approval and consent to participate}

This study was ruled exempt by the IRB and utilizes de-identified data from an international multi-institutional dataset. No individual consent for participation is required, as no individual data is included, and no human subjects were involved in the conduct of this study.

\section{Consent for publication}

This study uses an international multi-institutional deidentified dataset, so no additional consent for publication is required, as no human subjects were involved in the conduct of this study.

\section{Competing interests}

The authors declare that they have no competing interests.

\section{Author details}

'Division of Surgical Oncology, Department of Surgery, University of Nebraska Medical Center, 986880 Nebraska Medical Center, Omaha, NE 68198, USA. ${ }^{2}$ College of Medicine, University of Nebraska, Omaha, NE, USA. ${ }^{3}$ Department of Surgery, Brooke Army Medical Center, Fort Sam Houston, TX, USA. ${ }^{4}$ College of Public Health, Department of Biostatistics, University of Nebraska Medical Center, Omaha, NE, USA

Received: 23 November 2020 Accepted: 3 April 2021

Published online: 14 April 2021

\section{References}

1. Urbach DR, Kennedy ED, Cohen MM. Colon and rectal anastomoses do not require routine drainage: a systematic review and meta-analysis. Ann Surg. 1999:229:174-80.

2. Woods RS, Woods JF, Duignan ES, Timon C. Systematic review and metaanalysis of wound drains after thyroid surgery. Br J Surg. 2014;101:446-56.

3. Kim Yl, Fujita S, Hwang VJ, Nagase Y. Comparison of abdominal drainage and no-drainage after elective hepatectomy: a randomized study. Hepatogastroenterology. 2014;61:707-11.

4. Talving P, Mohseni S, Inaba K, et al. Closed suction drain after isolated hollow viscus injury: a friend or foe? J Trauma. 2011;70:1424-8.

5. Podda M, Di Saverio S, Davies RJ, et al. Prophylactic intra-abdominal drainage following colorectal anastomoses. A systematic review and metaanalysis of randomized controlled trials. Am J Surg. 2019. https://doi.org/1 0.1016/j.amjsurg.2019.05.006 [Epub ahead of print]

6. Kavuturu S, Rogers AM, Haluck RS. Routine drain placement in Roux-en-Y gastric bypass: an expanded retrospective comparative study of 755 patients and review of the literature. Obes Surg. 2012;22:177-81.

7. El Khoury R, Kabir C, Maker VK, Banulescu M, Wasserman M, Maker AV. Do drains contribute to pancreatic fistulae? Analysis of over 5000 pancreatectomy patients. J Gastrointest Surg. 2018;22:1007-15.

8. Conlon KC, Labow D, Leung $D$, et al. Prospective randomized clinical trial of the value of intraperitoneal drainage after pancreatic resection. Ann Surg. 2001:234:487-93.

9. Van Buren G 2nd, Bloomston M, Hughes SJ, et al. A randomized prospective multicenter trial of pancreaticoduodenectomy with and without routine intraperitoneal drainage. Ann Surg. 2014;259:605-12.

10. Van Buren $G$ 2nd, Bloomston M, Schmidt CR, et al. A prospective randomized multicenter trial of distal pancreatectomy with and without routine intraperitoneal drainage. Ann Surg. 2017;266:421-31.

11. Diener MK, Mehr KT, Wente MN, Kieser M, Büchler MW, Seiler CM. Riskbenefit assessment of closed intra-abdominal drains after pancreatic surgery: a systematic review and meta-analysis assessing the current state of evidence. Langenbecks Arch Surg. 2011;396:41-52.

12. Kawai M, Tani M, Terasawa $\mathrm{H}$, et al. Early removal of prophylactic drains reduces the risk of intra-abdominal infections in patients with pancreatic head resection: prospective study for 104 consecutive patients. Ann Surg. 2006;244:1-7.

13. Schmidt CM, Choi J, Powell ES, et al. Pancreatic fistula following pancreaticoduodenectomy: clinical predictors and patient outcomes. HPB Surgery. 2009. https://doi.org/10.1155/2009/404520 [Epub 2009 May 18].

14. Whitson BA, Richardson E, laizzo PA, Hess DJ. Not every bulb is a rose: a functional comparison of bulb suction devices. J Surg Res. 2009;156:270-3.

15. Kone LB, Maker VK, Banulescu M, Maker AV. Should drains suck? a propensity score analysis of closed-suction versus closed-gravity drainage after pancreatectomy. J Gastrointest Surg. 2020. https://doi.org/10.1007/s11 605-020-04613-7.

16. Lemke M, Park L, Balaa FK, Martel G, Abou Khalil J, Bertens KA. Passive versus active intra-abdominal drainage following pancreaticoduodenectomy: a retrospective study using the American College of Surgeons NSQIP database. World J Surgery. 2020;19:1-8. 
17. American College of Surgeons. ACS National Surgical Quality Improvement Program. Available: www.facs.org/quality-programs/acs-nsqip [accessed 1 Sept 2019].

18. Shiloach M, Frencher SK Jr, Steeger JE, et al. Toward robust information: data quality and inter-rater reliability in the American College of Surgeons National Surgical Quality Improvement Program. J Am Coll Surg. 2010;210: 6-16.

19. Bassi C, Marchegiani $G$, Dervenis C, et al. The 2016 update of the International Study Group (ISGPS) definition and grading of postoperative pancreatic fistula: 11 years after. Surgery. 2017;161:584-91.

20. Kantor O, Pitt HA, Talamonti MS, et al. Minimally invasive pancreatoduodenectomy: is the incidence of clinically relevant postoperative pancreatic fistula comparable to that after open pancreatoduodenectomy? Surgery. 2018;163:587-93.

21. Krell RW, McNeil LR, Yanala UR, Are C, Reames BN. Neoadjuvant therapy for pancreatic ductal adenocarcinoma: propensity-matched analysis of postoperative complications using ACS-NSQIP. Ann Surg Oncol. 2021. https://doi.org/10.1245/s10434-020-09460-z.

22. Callery MP, Pratt WB, Kent TS, Chaikof EL, Vollmer CM Jr. A prospectively validated clinical risk score accurately predicts pancreatic fistula after pancreatoduodenectomy. J Am Coll Surg. 2013;216:1-14.

23. Čečka F, Jon B, Skalický P, Čermáková E, Neoral Č, Loveček M. Results of a randomized controlled trial comparing closed-suction drains versus passive gravity drains after pancreatic resection. Surgery. 2018;164:1057-63.

24. Witzigmann $\mathrm{H}$, Diener MK, Kienkötter $\mathrm{S}$, et al. No need for routine drainage after pancreatic head resection: the dual-center, randomized, controlled PANDRA trial (ISRCTN04937707). Ann Surg. 2016;264:528-37.

25. Correa-Gallego C, Brennan MF, D'Angelica M, et al. Operative drainage following pancreatic resection: analysis of 1122 patients resected over 5 years at a single institution. Ann Surg. 2013;258:1051-8.

26. Miller BC, Christein JD, Behrman SW, et al. A multi-institutional external validation of the fistula risk score for pancreatoduodenectomy. J Gastrointest Surg. 2014;18:172-80,

27. McMillan MT, Malleo G, Bassi C, et al. Multicenter, prospective trial of selective drain management for pancreatoduodenectomy using risk stratification. Ann Surg. 2017;265:1209-18.

28. Bassi C, Molinari E, Malleo G, et al. Early versus late drain removal after standard pancreatic resections: results of a prospective randomized trial. Ann Surg. 2010:252:207-14.

29. Ven Fong Z, Correa-Gallego C, Ferrone CR, et al. Early drain removal-the middle ground between the drain versus no drain debate in patients undergoing pancreaticoduodenectomy. Ann Surg. 2015;262:378-83.

30. El Nakeeb A, Askr W, Mahdy Y, Elgawalby A, Zeied MA, Abdallah T. Delayed gastric emptying after pancreaticoduodenectomy. Risk factors, predictors of severity and outcome. A single center experience of 588 cases. J Gastrointest Surg. 2015;19:1093-100

31. Hu B, Tan HY, Rao XW, Jiang JY, Yang K. A scoring system for surgical site infection after pancreaticoduodenectomy using clinical data. Surg Infect (Larchmt). 2021;22:240-4.

32. Ramanathan R, Mason T, Wolfe LG, Kaplan BJ. Predictors of short-term readmission after pancreaticoduodenectomy. J Gastrointest Surg. 2018;22: 998-1006.

\section{Publisher's Note}

Springer Nature remains neutral with regard to jurisdictional claims in published maps and institutional affiliations.

Ready to submit your research? Choose BMC and benefit from:

- fast, convenient online submission

- thorough peer review by experienced researchers in your field

- rapid publication on acceptance

- support for research data, including large and complex data types

- gold Open Access which fosters wider collaboration and increased citations

- maximum visibility for your research: over $100 \mathrm{M}$ website views per year

At BMC, research is always in progress.

Learn more biomedcentral.com/submissions 